Nepal Journal of Science and Technology 12 (2011) 179-186

\title{
Isolation, Identification and Antimicrobial Activity of a Withanolide [WS-1] from the Roots of Withania somnifera
}

\author{
Prakash Kharel ${ }^{a}$, Mangala D. Manandharb, Surya K. Kalauni ${ }^{a}$, \\ Suresh Awale ${ }^{\mathrm{c}}$ and Janaki Baral ${ }^{\mathrm{a}}$ \\ ${ }^{a}$ Central Department of Chemistry, Tribhuvan University, Kathmandu \\ ${ }^{b}$ Nepal Academy of Science and Technology (NAST), Lalitpur \\ 'Institute of Natural Medicine, University of Toyama, 2630 Sugitani, Toyama, Japan
}

\begin{abstract}
Column chromatographic purification of the organic extract obtained from the roots of Withania somnifera yielded a biologically active withanolide compound WS-1 whose structure was established on the basis of spectroscopic evidences. Potent antibacterial activity was observed in this compound.
\end{abstract}

Key words: antimicrobial analysis, MIC, Withania, Withanolide, ZOI

\section{Introduction}

Withania somnifera, popularly known as Ashwagandha is one of the well known medicinal plant of traditional medicinal systemAyurveda (Anon 1996). In Ayurveda, this plant is claimed to have potent aphrodisiac rejuvenative and life prolonging properties (Vaidyaratnam 1994). It has general animating and regenerative qualities and is used among others for the treatment of nervous exhaustion, memory related conditions, insomnia, tiredness potency issues, skin problems and coughing. It is claimed that intake of Ashwagandha improves learning ability and memory capacity. The traditional use of Ashwagandha is supposed to increase energy, youthful vigour, endurance, strength, health, nurture the time elements of the body, vital fluids, muscle fat, blood, lymph, semen and cell production. It helps counteract chronic fatigue, weakness, dehydration, bone weakness, loose teeth, thirst, impotency, premature aging emaciation, debility, and muscle tension (Sangwan et al. 2004, Gupta \& Rana 2007). It helps invigorate the body by rejuvenating the reproductive organs, just as a tree is invigorated by feeding the roots.

Several of its traditionally proclaimed medicinal properties have been shown to be associated with its specific secondary metabolites known as withanolides, the novel group of ergostane skeletal phytosteroids, named after the plant (Gupta et al. 1998). They are C-28 steroidal lactones, built on an intact or re-arranged ergostane framework and they are found in both the aerial parts and roots. Withasteroids are subdivided according to their structural features as: (a) compounds unsubstituted at C-20, e.g. withaferin A, (b) compounds possessing a hydroxyl group at C-20 (20 $\alpha)$, e.g. withanolide D and (c) compounds in which the side chain is $\alpha$ oriented at C-17, e.g. withanolide E. 
Their pharmacological properties are diverse, ranging from anti-inflammatory, anti-tumour, antistress, anti-oxidant, immunomodulatory, hemopoetic and cardio-protective effects. This plant contains many structurally diverse withanolides in its leaves and roots (Sangwan et al. 2005).

From literature survey, the high repute of Withania somnifera in medicinal system was cleared (Sagwan et al. 2004), and it was found that the phytochemical and antimicrobial screening of the plant in the context of Nepal has not been determined yet. This has prompted us to undertake phytochemical and antimicrobial analysis of this plant.

\section{Methodology Equipment}

Rotatory evaporator used in the evaporation process was Kinematica rotavapor RV $60 \mathrm{ML}$, made in Switzerland. The NMR analysis was done with JEOL-JNM-LA 400WB Spectrometer at the University of Toyama, Sugitani Campus, Toyama, Japan.

\section{Solvents and chemicals}

All the organic solvents and chemicals were purchased from E. Merck, Glaxo, BDA, Qualigens, and Ranbaxy Chemical Companies of India and were of laboratory and analytical grade. Silica gel used for column chromatography was of 60-120 mesh size and obtained from S. D. Fine Chemicals Pvt. ltd. Precoated thin layer chromatography plates with Silica Gel $\left[60 \mathrm{GF}_{254}, 0.2 \mathrm{~mm}\right.$ ] were purchased from Merck, Darmstad, Germany.

\section{Plant materials}

The underground parts of Withania somnifera were collected from Butwal, Nepal in October 2009 and authenticated from Tribhuvan University Central Herbarium, Central Department of Botany, Kirtipur. The plant materials were air-dried under shade.

\section{Extraction}

The dried plant materials were powdered (1.5 $\mathrm{kg}$ ) and was first extracted with methanol (7.5 1) in a Sohxlet extractor. The solvent was evaporated under reduced pressure in a rotatory evaporator to get methanol extract $(150 \mathrm{~g})$.

\section{Fractionation of methanol extract}

The initially extracted methanol fraction (150 g) was re-extracted successively by hexane, chloroform and methanol to get the final extracts in the amount of $4 \mathrm{~g}, 3.5 \mathrm{~g}$ and $100 \mathrm{~g}$ respectively. Chloroform fraction was chosen for the present study and compounds were isolated by using column chromatography technique. Silica gel was used as an adsorbent and $60 \%$ ethylacetate in hexane was the eluting solvent for WS-1. [Identification of other two compounds is in progress]. These fractions were used in phytochemical screening and antibacterial screening as well.

\section{Antibacterial screening}

Inhibition of bacterial growth was tested by using the paper disc diffusion method (Perez, 1990 \& Khan 1997). The positive control used was tetracycline and negative control was methanol.

Collection of test organisms: The microbial strains employed were identified strains that were obtained from Central Department of Microbiology, TU, which include seven different types of bacteria, three Gram-positive (Bacillus subtilis, Klebsiela pneumonia and Staphylococcus aureus) and four Gram-negative (Escherichia coli, Proteus vulgaris, Pseudomonas aeruginosa and Salmonella typhi). They were first taken on slants and later cultured on petriplates having nutrient agar.

Preparation of the test discs: Sterile test discs were prepared by dipping and saturating sterilized filter paper discs in plant extract. Same sized filter paper discs (6 mm diameter), made by cutting the Whatman No. 1 filter paper with the help of punching machine, and absorbed the same volume of extract. For negative control methanol paper discs were used, prepared by dipping the disc into the methanol, while tetracycline paper discs were used as positive control. For tetracycline paper discs $10 \mathrm{ml}$ solution was prepared mixing $0.8 \mathrm{ml}$ tetracycline solution (prepared by dissolving 500mg tablets of tetracycline in $20 \mathrm{ml}$ methanol) with $9.2 \mathrm{ml}$ of methanol. The final concentration of tetracycline was $0.25 \mathrm{mg} / \mathrm{ml}$. 
Preparation of standard culture inoculums: Three to five colonies of similar appearance of the organism to be tested were aseptically touched with the help of inoculating loop from primary culture plate. It was transferred to a tube containing $10 \mathrm{ml}$ sterile liquid media of nutrient broth. The tube was incubated overnight inside the incubator at $37^{\circ} \mathrm{C}$.

Transfer of bacteria on petri plates: The agar plates for the assay were prepared by labeling them with date and name of bacteria and name code of the discs. The inoculums of bacteria were transferred into petridish containing solid nutrient media of agar using sterile swab. The sterile cotton swab was dipped into a well mixed saline test culture and removed excess inoculums by pressing the saturated swab against the inner wall of the culture tube. The swab was used to spread the bacteria on the media in a confluent lawn. It was done by rotating the petriplates at $90^{\circ}$ and continuing the spread of bacteria. One swab was used for one species of bacteria. The culture plates were allowed to dry for five minutes.

Placing test discs: Dried test discs were transferred on bacterial lawn under aseptic conditions using flame-sterilized forceps each time. Each disc was placed gently on the agar surface on equidistance and patted with the forceps to ensure the disc adhere to the surface of agar. The petriplates were incubated in an inverted position for 24 hours at $37^{\circ} \mathrm{C}$.

Observation of result: After 24 hour of incubation at $37^{\circ} \mathrm{C}$, results were recorded as the presence or absence of inhibition zones. Resulting zones of inhibition were observed and recorded as positive and negative. The diameter of zone of inhibition (ZOI) produced by plant extract on particular bacteria was also measured with the help of millimeter ruler. The inhibitory zone around test paper discs indicated absence of bacterial growth and that was recorded as positive and absence of zone as negative. Tests were repeated three times to insure the reliability of the results.

Determination of the minimum inhibitory concen-tration (MIC): A stock solution of 10 $\mathrm{mg} / \mathrm{ml}$ was pre-pared. This was serially diluted to obtain various ranges of concentrations between $0.5 \mathrm{mg}$ / $\mathrm{ml}$ to $10 \mathrm{mg} / \mathrm{ml}$.

\section{Phytochemical screening}

The method developed by Ciulie (1990) was followed for the phytochemical screening. The dried powder of plant-material was successively extracted with solvents of increasing polarity. The different classes of natural compounds present in the three extracts were detected specifically. The main objectives of phytochemical screening were to identify the main groups of chemical constituents present in different plant extracts. Different phytochemicals in various extracts were identified by the colour reaction with different reagents.

\section{Results and Discussion}

Fractions eluted with $60 \%$ ethyl acetate in hexane in column chromatography were found identical in TLC with single spot and hence these fractions were mixed and concentrated under reduced pressure. The concentrated white mass was washed with hexane and ether successively. This was recrystallized from alcohol and analyzed as WS-1.

\section{Structure elucidation of compound WS-1}

Compound WS-1 was a white amorphous solid with melting point $118^{\circ} \mathrm{C}$. It showed UV active spot on TLC with $\mathrm{R}_{\mathrm{f}} .0 .45$ [ solvent system used was hexane and ethyl acetate in the ratio of 2:3].

The mass spectrum of WS-1 showed the molecular ion peak at $\mathrm{m} / \mathrm{z} 470$ supporting the molecular formula as $\mathrm{C}_{28} \mathrm{H}_{38} \mathrm{O}_{6}$ and indicating ten degrees of unsaturation in the molecule [five degrees for five rings, two degrees for two $\mathrm{C}=\mathrm{C}$ bonds, two degrees for two $\mathrm{C}=\mathrm{O}$ bonds and one degree for epoxide] (Fig. 1). Peak at m/z 436 was due to the loss of two water molecules from parent molecule WS-1. The peak at $\mathrm{m} / \mathrm{z} 345$ was due to the loss of lactone ring side from main steroidal portion. The peak at $\mathrm{m} / \mathrm{z} 311$ symbolized the loss of two water molecules from remaining portion, indicating the presence of two hydroxyl groups in the compound. 


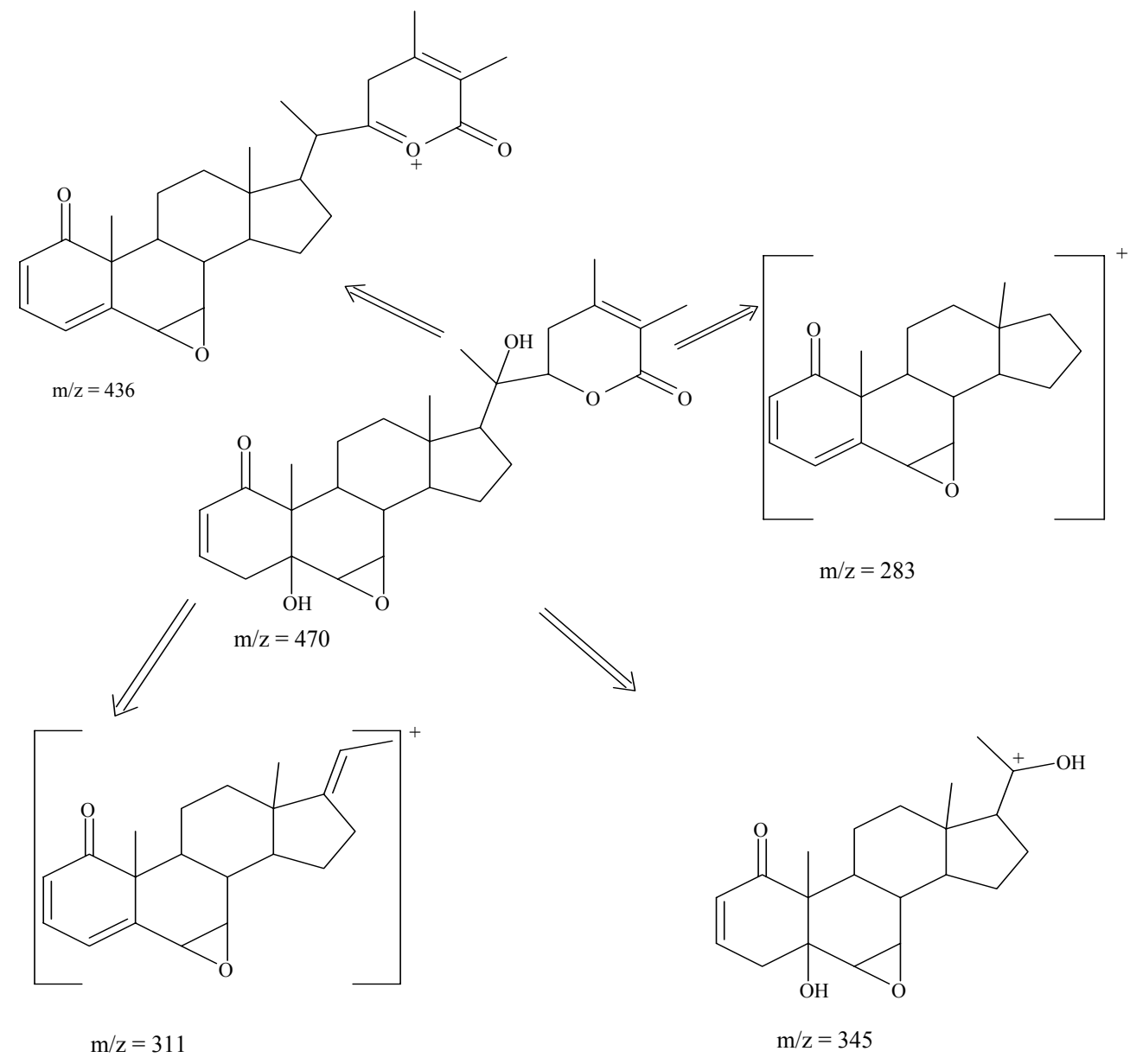

The ${ }^{1} \mathrm{H}$ - NMR spectrum of WS-1 featured singlets at $\delta 0.96,1.18,1.32,1.96$ and 1.89 due to five tertiary methyl groups (Table 1). A proton doublet of doublet at $\delta 5.84$ and one proton doublet of doublet of doublet at $\delta 6.58$ were assigned to vinylic protons at $\mathrm{H}-2$ and $\mathrm{H}-3$, respectively. Two double doublets at $\delta 2.51$ and 2.54 were due to $\mathrm{H}-4 \alpha$ and $\mathrm{H}-4 \beta$ protons, respectively. A broad singlet at $\delta 3.13$ is due to the hydroxyl proton attached at $\mathrm{C}-5$. The $\mathrm{C}-22$ methine proton was appeared as a doublet of doublet at $\delta 4.2$.

The ${ }^{1} \mathrm{H}$ - NMR spectrum of WS-1 was characteristic for the steroidal structure of the withanolide group
(Farzana 1997). The signals of two vinylic methyl groups, Me-27 and Me-28, and the characteristic H-22 signal confirmed the presence of $\alpha, \beta$-unsaturated lactone ring as side chain of the withanolide. The pattern and coupling constant values of $\mathrm{H}-22$ signal and the chemical shift of Me-21 were indicative of a 20$\mathrm{OH}$ compound.

The configuration was assigned by analogy with other known withanolides. The position of Me18 signal was similar to that of the other withanolides characterized by unsubstituted C, D rings such as withanolide R (Farzana 1997). 
Prakash Kharel et al./Asolation, Identification........

Table 1. ${ }^{1} \mathrm{H}$ - NMR and ${ }^{13} \mathrm{C}$ - NMR data of WS-1

\begin{tabular}{|c|c|c|c|}
\hline Carbon No. & ${ }^{13} \mathrm{C}$ - NMR Chemical Shift $[\delta]$ & DEPT Multiplicity & ${ }^{1} H$ - NMR Chemical Shift $[\delta]$ \\
\hline 1 & 203.14 & $-\mathrm{C}-$ & - \\
\hline 2 & 129.02 & $\mathrm{CH}$ & dd 5.84 \\
\hline 3 & 139.56 & $\mathrm{CH}$ & ddd 6.58 \\
\hline 4 & 36.74 & $\mathrm{CH}_{2}$ & dd 2.52 \\
\hline 5 & 75.07 & $-\mathrm{C}-$ & - \\
\hline 6 & 56.31 & $\mathrm{CH}$ & d 3.04 \\
\hline 7 & 57.29 & $\mathrm{CH}$ & dd 3.31 \\
\hline 8 & 26.8 & $\mathrm{CH}$ & dd 2.67 \\
\hline 9 & 35.55 & $\mathrm{CH}$ & d 1.75 \\
\hline 10 & 51.00 & $-\mathrm{C}-$ & - \\
\hline 11 & 23.19 & $\mathrm{CH}_{2}$ & $\mathrm{~m} 1.57$ \\
\hline 12 & 35.05 & $\mathrm{CH}_{2}$ & $\mathrm{~m} 2.1$ \\
\hline 13 & 43.86 & $-\mathrm{C}-$ & - \\
\hline 14 & 51.93 & $\mathrm{CH}$ & $\mathrm{m} 1.56$ \\
\hline 15 & 21.82 & $\mathrm{CH}_{2}$ & $\mathrm{~m} 1.74$ \\
\hline 16 & 21.73 & $\mathrm{CH}_{2}$ & $\mathrm{~m} 1.74$ \\
\hline 17 & 40.8 & $\mathrm{CH}$ & $\mathrm{m} 1.54$ \\
\hline 18 & 21.06 & $\mathrm{CH}_{3}$ & s 0.96 \\
\hline 19 & 20.53 & $\mathrm{CH}_{3}$ & s 1.18 \\
\hline 20 & 73.24 & $-\mathrm{C}-$ & - \\
\hline 21 & 14.72 & $\mathrm{CH}_{3}$ & s 1.32 \\
\hline 22 & 81.01 & $\mathrm{CH}$ & dd 4.20 \\
\hline 23 & 31.68 & $\mathrm{CH}_{2}$ & $\mathrm{~m} 2.32$ \\
\hline 24 & 148.77 & $-\mathrm{C}-$ & - \\
\hline 25 & 122.05 & $-\mathrm{C}-$ & - \\
\hline 26 & 166.10 & $-\mathrm{C}-$ & - \\
\hline 27 & 12.45 & $\mathrm{CH}_{3}$ & s 1.96 \\
\hline 28 & 13.75 & $\mathrm{CH}_{3}$ & s 1.89 \\
\hline
\end{tabular}


The ${ }^{1} \mathrm{H}$ - NMR spectrum of WS-1 was characteristic for the steroidal structure of the withanolide group (Farzana 1997). The signals of two vinylic methyl groups, Me-27 and Me-28, and the characteristic $\mathrm{H}-22$ signal confirmed the presence of $\alpha, \beta$-unsaturated lactone ring as side chain of the withanolide. The pattern and coupling constant values of $\mathrm{H}-22$ signal and the chemical shift of Me-21 were indicative of a 20$\mathrm{OH}$ compound.

The configuration was assigned by analogy with other known withanolides. The position of Me18 signal was similar to that of the other withanolides characterized by unsubstituted C, D rings such as withanolide R (Farzana 1997).

The ${ }^{13} \mathrm{C}-\mathrm{NMR}$ spectrum showed the presence of twenty eight peaks. DEPT spectrum showed the presence of five methyl, six methylene and ninemethine carbons. So, remaining eight carbons must be quaternary carbons. Peak at $\delta$ 203.14 was assigned for $\mathrm{C}-1$ carbonyl carbon and peak at $\delta 166.10$ was assigned for C-26

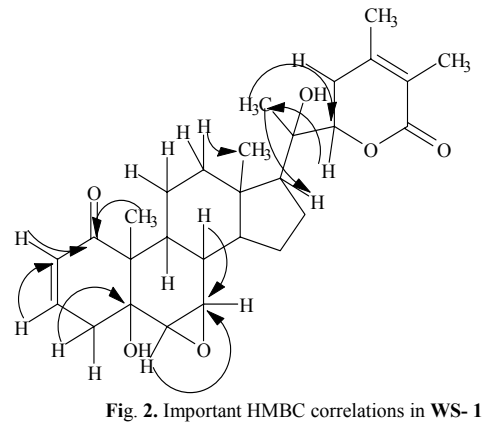

The HMBC correlations of $\mathrm{H}_{2}-4$ protons at $\delta$ 2.52 [dd] and H-6 proton at $\delta 3.04$ [d] with oxygenated carbon $\mathrm{C}-5$ at $\delta 75.07$ proved the presence of hydroxyl group at C-5. H-6 at $\delta 3.04$ [d] was found to be coupled with $\mathrm{H}-7$ at $\delta 3.31$ [dd] in COSY spectrum. The later also exhibited coupling interaction with $\mathrm{C}-8$ methine proton at $\delta$ 2.67. The H-8 methine proton also showed cross peaks with $\mathrm{H}-9$ methine protons at $\delta 1.75$; later in turrn showed vicinal coupling with the $\mathrm{H}_{2}-11$ methylene protons. $\mathrm{H}_{2}-11$ protons exhibited COSY interaction with $\mathrm{H}_{2}-12$ methylene protons at $\delta 2.1$. The relatively high $\delta$ values of C-6 and C-7 [also H-6 and H-7] showed the presence of epoxide ring there. The HMBC correlation of $\mathrm{H}_{3}-19$ at $\delta 1.18$ [s] with carbonyl carbon at $\delta 203.14$ proves $\mathrm{C}-1$ as carbonyl carbon. $\mathrm{H}_{3}-19$ protons show correlations with $\mathrm{C}-9$ at $\delta 35.55$ and with $\mathrm{C}-10$ at $\delta 51.0$ as well. lactone carbonyl carbon. Peaks at $\delta$ 129.02, $139.56,148.77$ and 122.05 were due to the presence of four vinylic carbons. There are eight quaternary carbons in the molecule resonated at $\delta 203.14,166.10,148.77,122.05,75.07,73.24$, 51.00 , and 43.86 as deduced by comparing DEPT spectrum with broad-band decoupled spectrum. These features along with the informations from mass spectral data and ${ }^{1} \mathrm{H}$ NMR data suggest the compound as a withanolide.

The structure was largely determined on the basis of long range heteronuclear correlations observed between protons and carbons of various spin systems and by comparision of NMR data with that of different withanolides. Analysis of COSY spectrum led to partial structure which was connected on the basis of HMBC correlations (Fig. 2 and Fig. 3). H-2 proton $\delta$ $5.84[\mathrm{dd}]$ correlates with $\mathrm{H}-3$ proton at $\delta 6.58$ [ddd] and H-2 shows HMBC correlation with C1 indicating the presence of double bond between $\mathrm{C}-2$ and $\mathrm{C}-3$.

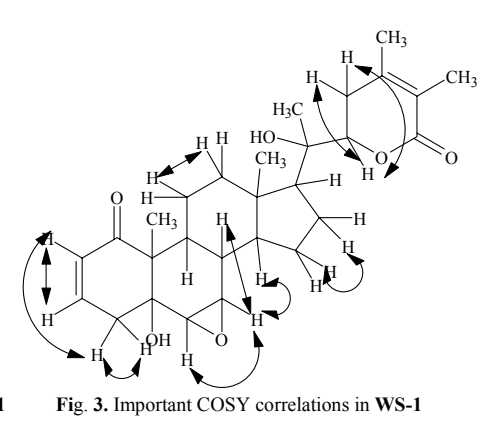

In COSY spectrum, $\mathrm{H}-7$ at $\delta 3.31$ [dd] showed correlation with $\mathrm{H}-8$ at $\delta 2.67$ [dd] and in $\mathrm{HMBC}$ H-8 showed correlation with C-7, C-9 and C-14. $\mathrm{H}_{3}-18$ Protons at $\delta 0.96[\mathrm{~s}]$ showed correlation with $\mathrm{C}-12$ at $\delta 40.38, \mathrm{C}-14$ at $\delta 51.93$ and C-17 at $\delta 35.05$, showing steroidal nature of the ring. $\mathrm{H}_{3}-21$ Protons at $\delta 1.32[\mathrm{~s}]$ are more deshielded due to the presence of $\mathrm{OH}$ group in $\mathrm{C}-20$ and $\mathrm{H}$ 21 showed HMBC correlation with $\mathrm{C}-20$ at $\delta$

73.24. H-22 [dd, $\delta$ 1.32] is more deshielded due to the presence of lactonic oxygen in the adjacent position. H-22 showed HMBC correlation with $\mathrm{C}-20$ and $\mathrm{C}-23$ also. $\mathrm{H}_{3}-28$ protons showed HMBC correlation with lactone carbonyl carbon $\mathrm{C}-26$ at $\delta 166.10$ and with olefinic carbon C-25 at $\delta$ 122.10, while $\mathrm{H}_{3}-27$ protons showed correlation with $\mathrm{C}-24$ and $\mathrm{C}-23$. Comparison of NMR data of C-6/ C-7 and H-6/ H-7 of WS-1 with that of withanolide $\mathrm{A}$ and other withanolides suggests the $\beta$-stereochemistry of 
epoxide (Farzana 1997 \& Subramanian 1971). This fact is further supported by the relative shift of ${ }^{1} \mathrm{H}$ and ${ }^{13} \mathrm{C}$ NMR signals of ring $\mathrm{B}$ and $\mathrm{C}$ as well. Hence, the following structure was confirmed for the isolated withanolide WS-1 (fig 4).

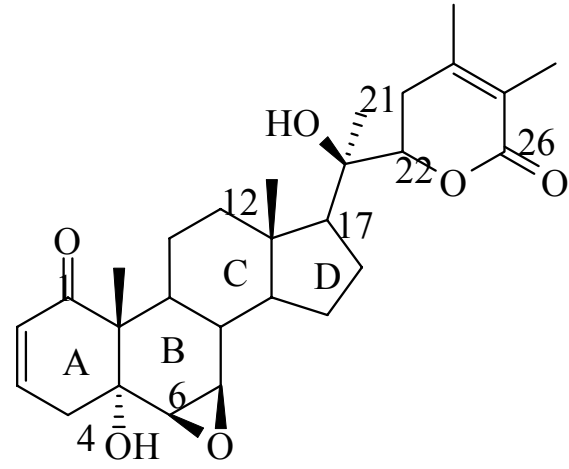

Percentage yield of WS-1 was $0.0156 \%$ by weight.

\section{Phytochemical screening}

The result of phytochemical screening indicated the presence of steroids, withanolides, terpenoids, alkaloids and glycosides as the major constituents of root of $W$. somnifera.

\section{Antibacterial activity of WS-1}

The minimum inhibitory concentration [MIC] and zone of inhibition [ZOI] study of WS-1 in concentration dependent manner revealed that it is active against many bacteria in concentration equal to or higher than $2 \mathrm{mg} / \mathrm{ml}$. This compound showed very high antibacterial activity against all tested bacteria except Proteus vulgaris.

Fig. 4. Structure of WS-1

Table 2 MIC and ZOI (in mm) of WS-1 in different concentrations

\begin{tabular}{|c|c|c|c|c|c|c|c|c|c|}
\hline $\operatorname{Conc}^{\mathrm{n}}[\mathrm{mg} / \mathrm{ml}]$ & 1.0 & 2.0 & 3.0 & 5.0 & 6.0 & 7.0 & 8.0 & 9.0 & 10.0 \\
\hline $\begin{array}{l}\text { Bacteria } \underset{ }{\downarrow} \boldsymbol{\downarrow} \text { aeruginosa }\end{array}$ & 0 & $6.66 \pm 0.57$ & $8 \pm 1$ & $10 \pm 1.73$ & $11.66 \pm 1.52$ & $11.66 \pm 1.15$ & $13.66 \pm 0.57$ & $15.33 \pm 0.57$ & $17 \pm 1$ \\
\hline S. aureus & 0 & $6.66 \pm 0.57$ & $8 \pm 1$ & $9 \pm 1.73$ & $11.66 \pm 2.08$ & $13.66 \pm 1.15$ & $14.33 \pm 0.57$ & $15.66 \pm 0.57$ & $17.33 \pm 1.52$ \\
\hline B. subtilis & 0 & $7 \pm 1$ & $8 \pm 1$ & $10.33 \pm 0.57$ & $13.33 \pm 1.15$ & $12.33 \pm 1.15$ & $13.66 \pm 1.15$ & $16 \pm 1$ & $17.66 \pm 1.52$ \\
\hline P. vulgaris & 0 & 0 & 0 & 0 & 0 & 0 & $6.33 \pm 0.57$ & $7 \pm 1$ & $8.33 \pm 0.57$ \\
\hline S. typhi & 0 & $7 \pm 1$ & $9 \pm 1$ & $10.66 \pm 0.57$ & $12.66 \pm 0.57$ & $14.33 \pm 1.52$ & $15.66 \pm 0.57$ & $16.33 \pm 1.52$ & $18 \pm 1$ \\
\hline E. coli & 0 & $7 \pm 1$ & $8.33 \pm 1.52$ & $11.66 \pm 0.57$ & $14 \pm 1$ & $15.66 \pm 1.15$ & $17 \pm 1$ & $18 \pm 1$ & $19.33 \pm 3.05$ \\
\hline K. pneumonia & 0 & $7.66 \pm 0.57$ & $8 \pm 1$ & $11.66 \pm 1.15$ & $13.66 \pm 1.52$ & $14.66 \pm 0.57$ & $16.66 \pm 1.52$ & $18.33 \pm 0.57$ & $20.66 \pm 2.08$ \\
\hline
\end{tabular}

From the roots of $W$. somnifera of Nepal, a withanolide compound was isolated as WS -1 , which has shown potent antimicrobial activity.

\section{References}

Anon. 1996. The Useful Plants of India. PID, CSIR, New Delhi, pp. 918.

Ciulie, I. 1990. Methods of studying drug. Personal Communication.
Farzana, A. 1997. Isolaation and structural studies on the chemical constituents of Withania somnifera \& Fumaria flabellata and X-ray diffraction studies. $\mathrm{Ph}$. D. dissertation, University of Karachi, Pakistan.

Gupta, A., S. K. Vat and B. Lal. 1998. Current Science 74 : 565-566.

Gupta, G. L. and A. C. Rana. 2007. Pharmacognosy Reviews $\mathbf{1 .}$ 
Khan, Z. K. 1997. In vitro screening techniques for antibacterial and antifungal activity of medicinal plants. International Workshop on Medicinal Plants- Their Bioactivity Screening and Evaluation, CDRI, India, pp 4.

Perez, C., M. Paul and P. Bazerque. 1990. Antibiotic assay by agar well diffusion method. Acta Bio Medicine Experimentals, 15: 113-115.

Sangwan, R. S., N. D.Chaurasiya, L. N. Misra, G. C. Uniyal, R. Sharma, N. S. Sangwan, K. A. Suri, G. N. Qazi and R. Tuli. 2004. Phytochemical variability in commercial herbal products and preparations of Withania sominifera . Current Science, 86: 461-465.

Sangwan, R. S., N. D.Chaurasiya, L. N. Misra, G. C. Uniyal, R. Sharma, N. S. Sangwan, K. A. Suri, G. N. Qazi and R. Tuli, 2005. An improved process for isolation of withaferin-A from plant materials and products therefrom. US Patent. 7: 108, 870.

Subramanian, S. S. and P. D. Sethi. 1971. Phytochemistry, 10: 658-688.

Vaidyaratnam, P. S. 1994. Indian medicinal plants, a compendium of 500 species, Orient longman Publication, Hyderabad, India. pp 52-55. 